\title{
Study on the Effect of Oxygen Defects on the Electrical and Optical Properties of Thin Films
}

\author{
Jin Jeong $\mathbb{D}$ \\ Department of Physics, Chosun University, 309 Pilmun-daero, Dong-gu, Gwangju 501-759, Republic of Korea \\ Correspondence should be addressed to Jin Jeong; jeji@chosun.ac.kr
}

Received 29 August 2017; Revised 20 October 2017; Accepted 19 March 2018; Published 24 April 2018

Academic Editor: Jessem Landoulsi

Copyright (C) 2018 Jin Jeong. This is an open access article distributed under the Creative Commons Attribution License, which permits unrestricted use, distribution, and reproduction in any medium, provided the original work is properly cited.

\begin{abstract}
$\mathrm{SnO}_{2}$ thin films grown directly on the $\mathrm{Si}$ substrate had larger average grain sizes as the power intensity increased, but the average grain size of the $\mathrm{SnO}_{2}$ thin films grown in oxygen atmosphere decreased as the power intensity increased. Hall measurement of pure $\mathrm{SnO}_{2}$ thin films showed that the carrier density increased with increasing power. However, upon annealing the $\mathrm{SnO}_{2}$ thin films, the carrier density decreased with increasing power owing to the formation of oxygen vacancies and the $\mathrm{SiO}_{2}$ layer between the $\mathrm{Si}$ substrate and $\mathrm{SnO}_{2}$ thin films. The photoluminescence $(\mathrm{PL})$ of the $\mathrm{SnO}_{2}$ thin film grown in the oxygen atmosphere changed, and it was affected by the oxygen defects at the surface and interfaces of the thin film.
\end{abstract}

\section{Introduction}

The $\mathrm{SnO}_{2}$ thin film has a transparent electrode and has a transparent electrode for a display, a solar cell, a transparent thermal element, and an electric element [1-4]. The $\mathrm{SnO}_{2}$ thin film is manufactured by spray, chemical vapor deposition, and sputtering $[3,5-8]$. It can be manufactured in large amounts by sputtering, making the products less expensive. However, those manufactured by sputtering have defects caused by variation in temperature, deposition time, amount of oxygen in the chamber, amount of plasma generated (owing to the change in the supply power intensity), and vacuum in the chamber. Jeong et al. reported that the initial state of the substrate when a thin film grows can affect the electrical and optical properties of the thin film [9]. Therefore, in order to improve the electrical and optical properties of the $\mathrm{SnO}_{2}$ thin film, it is necessary to secure the reliability of the thin film and to control the defects in the thin film.

\section{Experimental Details}

To manufacture the $\mathrm{SnO}_{2}$ thin film by radio frequency (RF) sputtering, the $\mathrm{Sn}$ target is installed in the chamber, and power is supplied to the chamber to make plasma, so that the $\mathrm{Sn}^{+}$ions are dropped onto the metal Si substrate in the chamber and simultaneously, the high-purity oxygen
(99.99\%) is injected to deposit the $\mathrm{SnO}_{2}$ thin film. At this time, the amount of $\mathrm{Sn}+$ ions to be dropped is closely related to the amount of plasma in the chamber, which is influenced by the power intensity in the chamber. In this experiment, the thin film was grown by changing the deposition temperature in the chamber to $350^{\circ} \mathrm{C}$; the amount of oxygen introduced was $40 \mathrm{sccm}$; the deposition time was $1 \mathrm{~h}$; and the power was changed to 100, 150, and $200 \mathrm{~W}$ (S1, S2, and S3). Further, S4, $\mathrm{S} 5$, and $\mathrm{S} 6$ thin films were deposited on the Si substrate at a temperature of $350^{\circ} \mathrm{C}$ and an oxygen flow rate of $40 \mathrm{sccm}$, and then the powers supplied at the same conditions as S1, S2, and S3 films were 100, 150, and $200 \mathrm{~W}$. The experimental conditions are listed in Table 1.

The shapes and average sizes of the thin films were measured by electron microscopy (SEM, Hitachi, S-4700, Japan), and the structural characteristics of the thin films were determined by studying their X-ray diffraction (XRD, Rigaku, Rix-2000, Japan) patterns. The electrical properties of the $\mathrm{SnO}_{2}$ thin films were measured using a Hall effect measuring device (HL5500PC, England). The PL of the thin films was measured at room temperature.

\section{Results and Discussion}

Figure 1(a) shows the XRD results of the films grown at a constant power of 100,150 , and $200 \mathrm{~W}$ at a deposition 
TABLE 1: Condition of $\mathrm{SnO}_{2}$ thin films.

\begin{tabular}{|c|c|c|c|c|c|c|c|}
\hline Sample & $\begin{array}{c}\text { Power } \\
{[\mathrm{W}]}\end{array}$ & $\begin{array}{l}\text { O flow } \\
{[\mathrm{sccm}]}\end{array}$ & $\begin{array}{c}\text { Deposition temp. } \\
{\left[{ }^{\circ} \mathrm{C}\right]}\end{array}$ & $\begin{array}{c}\text { Deposition time } \\
\text { [hr] }\end{array}$ & $\begin{array}{c}\text { Preoxygen time } \\
{[\mathrm{hr}]}\end{array}$ & $\begin{array}{c}\text { Thickness } \\
(\mathrm{nm})\end{array}$ & $\begin{array}{c}\text { Grain size } \\
(\mathrm{nm})\end{array}$ \\
\hline S1 & 100 & 40 & 350 & 1 & & 10 & 23 \\
\hline S2 & 150 & 40 & 350 & 1 & & 25 & 22 \\
\hline S3 & 200 & 40 & 350 & 1 & & 40 & 27 \\
\hline S4 & 100 & 40 & 350 & 1 & 1 & 12 & 26 \\
\hline S5 & 150 & 40 & 350 & 1 & 1 & 30 & 27 \\
\hline S6 & 200 & 40 & 350 & 1 & 1 & 50 & 29 \\
\hline
\end{tabular}

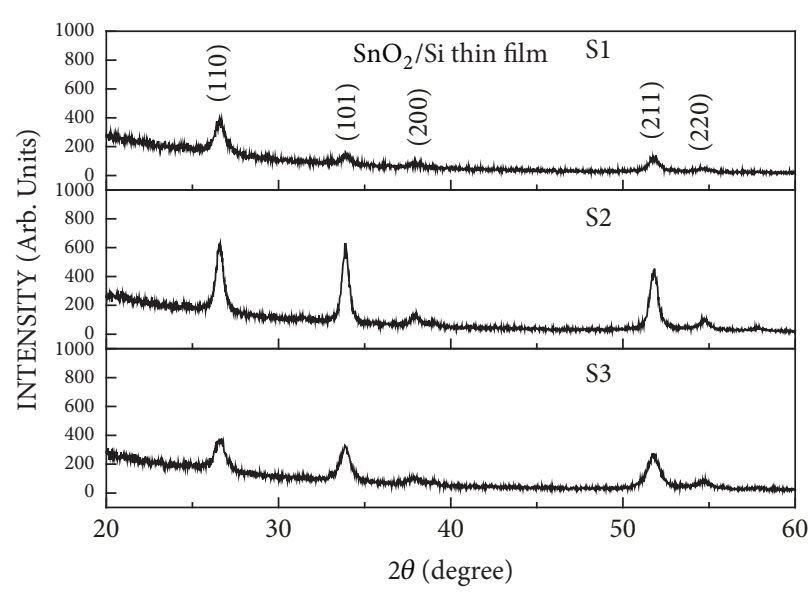

(a)

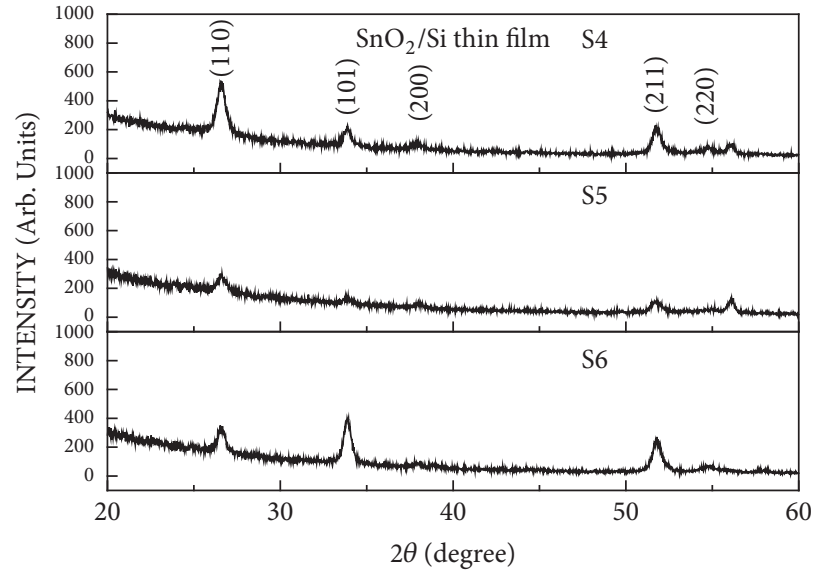

(b)

FIGURE 1: X-ray diffraction patterns of the $\mathrm{SnO}_{2}$ thin films of S-1, S-2, and S-3 groups (a) and S-4, S-5, and S-6 groups (b).

temperature of $350^{\circ} \mathrm{C}$, a deposition time of $1 \mathrm{~h}$, and an oxygen flow rate of $40 \mathrm{sccm}$. When the intensity of the supplied power was increased (110), both the (101) plane and the (211) plane had a tendency for crystal growth.

Figure 1(b) shows the XRD results obtained after thin film formation under conditions similar to those for S1, S2, and $\mathrm{S} 3$, after oxygen had flowed on the Si substrate for $1 \mathrm{~h}$ before the thin film was deposited. The (110), (211), and (101) planes of the thin films increased in intensity as the growth surface decreased. The thin film growth by sputtering is influenced by the power supplied to the chamber. XRD peaks are related to the density of the thin film and the density of the thin film will change as the amount of plasma supplied changes. Figure 1(a) shows that the intensity of the XRD peaks of the thin film is increased and decreased when the power supplied to the chamber is increased to 100,150 , and $200 \mathrm{w}$. It is seen that the density of the thin film is decreased by decreasing the density of the thin film, which seems to agree with the result of Figure 1(b). Jeong et al. [10, 11] reported that the growth direction of the thin film may change according to the initial growth conditions of thin films. The initial growth condition can be an important parameter in the grain growth of thin films, and changes in the growth surface of the thin film will change the particle shape, particle size, and electrical characteristics of the thin film [12].

Figure 2 shows the surface of S1, S2, and S3 thin films grown at a deposition temperature of $350^{\circ} \mathrm{C}$, a deposition time of $1 \mathrm{~h}$, an oxygen flow rate of $40 \mathrm{sccm}$, and supplied powers of 100,150 , and $200 \mathrm{~W}$. The thin films were circular, and the particle sizes increased with the supplied power. The shape of the thin film and the particle size are correlated with the intensity of the crystal face of the thin film. If the particle size changes, the strength and direction of the growth surface of the thin film may change.

Further, Figure 2(b) shows the $\mathrm{SiO}_{2}$ layers deposited by supplying oxygen onto the $\mathrm{Si}$ substrate; the thin films were then formed under identical conditions as those for S1, S2, and S3 thin films. The thin films are circular, as in the case of S1, S2, and S3 thin films and the particle size increases with the supplied power. Further understanding of microstructural evolution could be achieved considering that the starting material exhibits structural defects which, as proposed by Cirera et al. [13], are related to high oxygen vacancy concentration.

Figure 3 shows the average particle sizes of S1-S6 films. The average particle sizes of S1, S2, and S3 thin films are 23, 22, and $27 \mathrm{~nm}$, respectively. The average particle sizes of S4, S5, and S6 thin films sintered in an oxygen atmosphere are 26,27 , and $29 \mathrm{~nm}$, respectively. The average size spacing of S4, S5, and S6 films sintered in an oxygen atmosphere was less than that of S1-S3 films. When the $\mathrm{SnO}_{2}$ thin film is grown after oxygen flows over the $\mathrm{Si}$ substrate, the average particle size of the $\mathrm{SnO}_{2}$ thin film is influenced by the $\mathrm{SiO}_{2}$ layer, and hence, the deviation is 

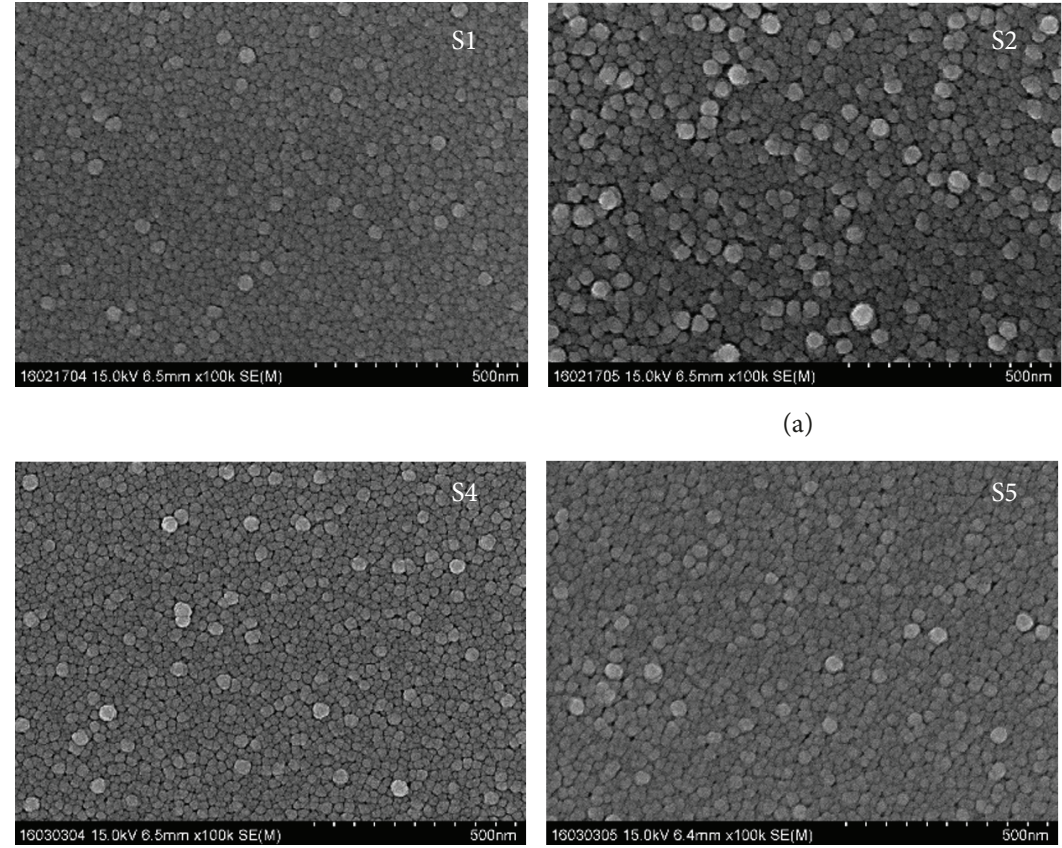

(b)
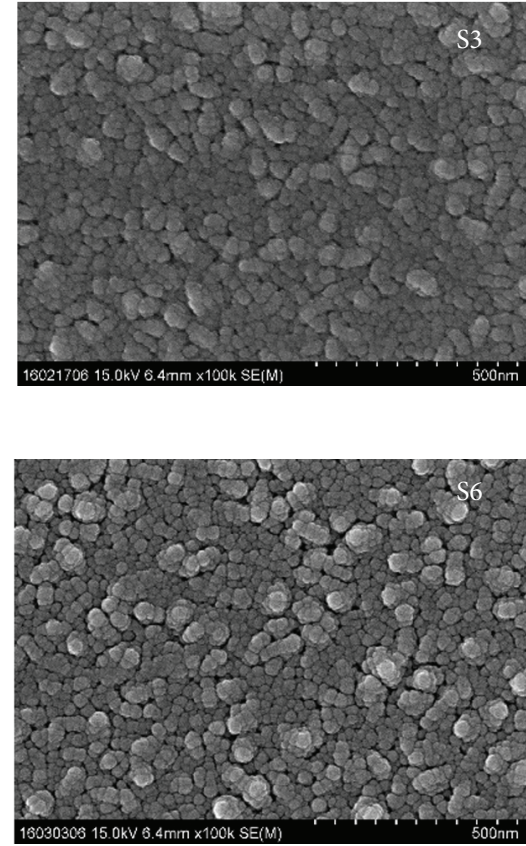

Figure 2: SEM images of the surface of the $\mathrm{SnO}_{2}$ thin films of S-1, S-2, and S-3 groups (a) and S-4, S-5, and S-6 groups (b).

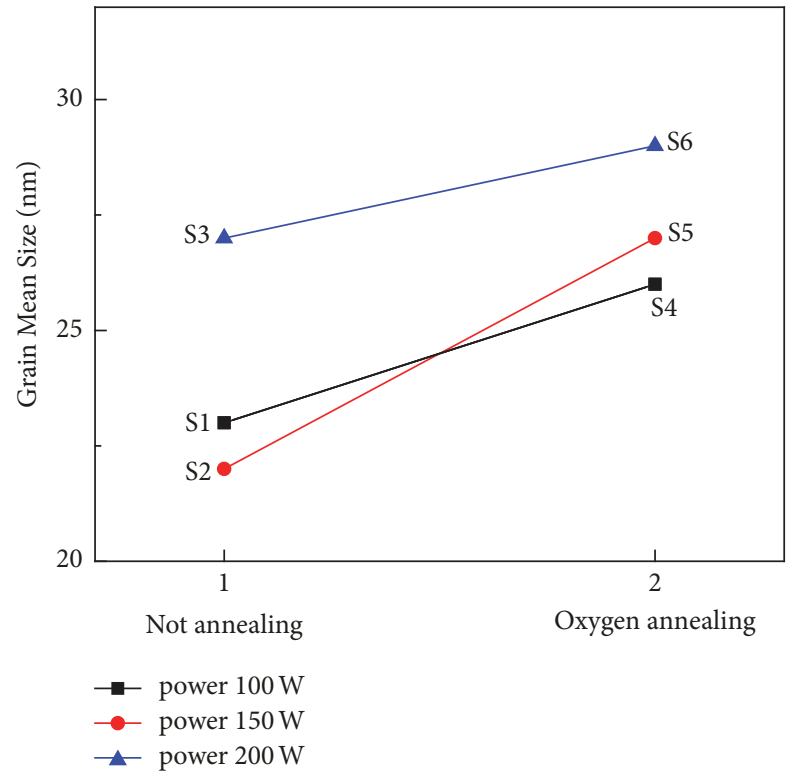

FIgURE 3: Mean grain size of the $\mathrm{SnO}_{2}$ thin films of S-1, S-2, and S-3 groups (1) and S-4, S-5, and S-6 groups (2).

reduced even if the power intensity of the particles is increased.

Figure 4 shows the mobility and surface charge density of the thin film obtained through the Hall measurement of thin films S1 to S6; the mobility of S1-S6 was 11.9, 7.41, 7.31, $10.2,8.24$, and 3.39 , respectively. The mobility of the thin film decreased as the supplied power increased, and it decreased uniformly when the power supplied to thin films S4, S5,

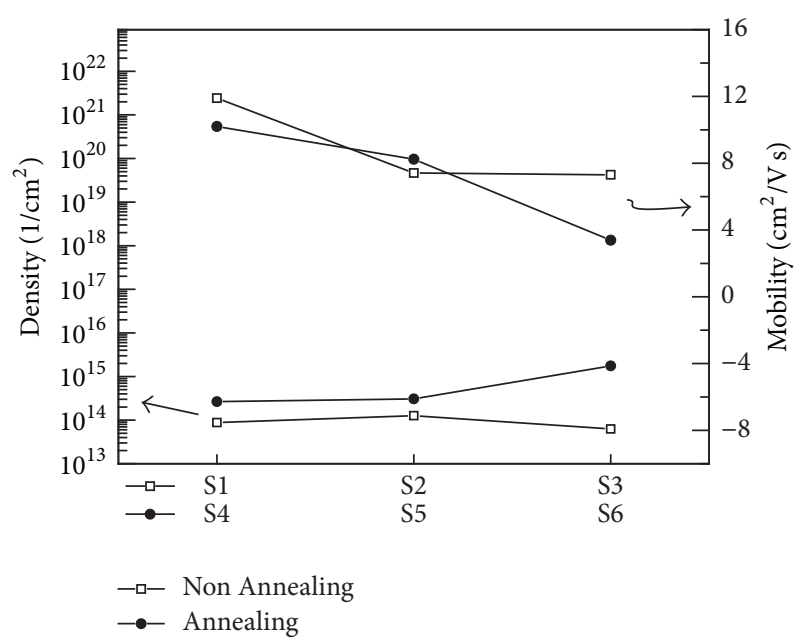

Figure 4: Hall effect data of the $\mathrm{SnO}_{2}$ thin films.

and S6 was increased in the oxygen atmosphere. Thus, the intensity of power supplied to the thin film seems to affect the mobility in the thin film. The surface charge densities of S1, S2, and S3 increased to $8.785 \times 10^{13}, 1.266 \times 10^{14}$, and 6.246 $\times 10^{13}$, respectively. That is, the intensity of power supplied when the thin film was deposited affects the transport charge density of the thin film. The surface charge densities of S4, S5, and S6 films sintered in the oxygen atmosphere were 2.646 $\times 10^{14}, 3.071 \times 10^{14}$, and $1.747 \times 10^{15}$, respectively, and the transport charge density of S4-S6 when the same power as that for S1-S3 was supplied was slightly larger than that of $\mathrm{S} 1-\mathrm{S} 3$. This is because the $\mathrm{SiO}_{2}+\mathrm{SnO}_{2}$ thin film formed on 
TABLE 2: Hall coefficient.

\begin{tabular}{lccc}
\hline Sample & Resistivity $(\mathrm{ohm} \mathrm{cm})$ & Carrier density $\left(\mathrm{cm}^{-2}\right)$ & Mobility $\left(\mathrm{cm}^{2} / \mathrm{V}\right.$-s $)$ \\
\hline S1 & $0.5984 \times 10^{4}$ & $8.785 \times 10^{13}$ & 11.9 \\
S2 & $0.6651 \times 10^{4}$ & $1.266 \times 10^{14}$ & 7.41 \\
S3 & $1.368 \times 10^{4}$ & $6.246 \times 10^{13}$ & 7.31 \\
S4 & $0.2310 \times 10^{4}$ & $2.646 \times 10^{14}$ & 10.2 \\
S5 & $0.2467 \times 10^{4}$ & $3.071 \times 10^{14}$ & 8.24 \\
S6 & $0.1054 \times 10^{4}$ & $1.747 \times 10^{15}$ & 3.39 \\
\hline
\end{tabular}

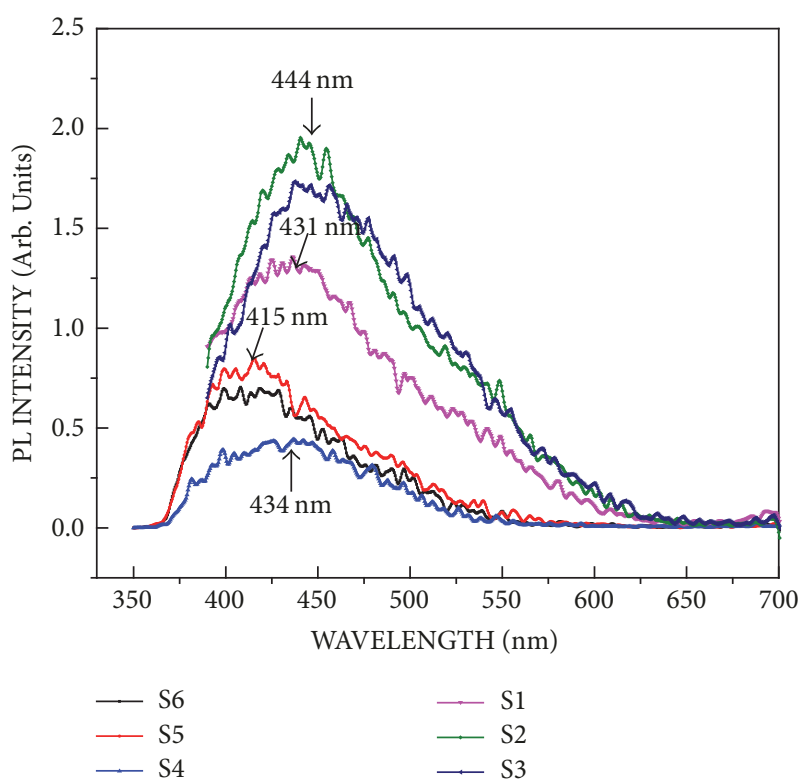

Figure 5: Photoluminescence spectra of the $\mathrm{SnO}_{2}$ thin films.

the Si substrate, and the carrier density increases because of the larger amount of oxygen than that present in the pure $\mathrm{SnO}_{2}$ thin film. It was confirmed that the intensity of supplied power affects the surface charge density and the mobility of the thin film and thus that the $\mathrm{SiO}_{2}$ layer between the $\mathrm{Si}$ substrate and the $\mathrm{SnO}_{2}$ thin film affects the electrical properties of the thin film [14]. In general, the fast growth rate of the thin film causes the poor electrical and optical properties due to the increase of roughness and pin hole. In Figures 4 and 5, the decrease in mobility and PL intensity in S3 and S6, which have the largest power during film growth, appears to be due to the poor thin film properties.

Figure 5 shows the PL measurement of thin films S1-S6. The PL intensities of S4, S5, and S6 films with $\mathrm{SiO}_{2}$ layer were less than those of S1, S2, and S3 films. In the case of S4, S5, and S6 films, the emission wavelengths of $431 \mathrm{~nm}$ and $444 \mathrm{~nm}$ (corresponding to S1-S3 films) shifted to $434 \mathrm{~nm}$ and $415 \mathrm{~nm}$, respectively. The $\mathrm{SnO}_{2}$ thin film grown on the $\mathrm{SiO}_{2}$ layer has different oxygen defects on the film surface, and the interface between the substrate and the thin film is different from that between the substrate and pure $\mathrm{SnO}_{2}$ thin film: the emission peak shift of the photoluminescence. This is consistent with the change in the carrier density of the surface of the $\mathrm{SnO}_{2}$ thin film, as presented in Table 2.

\section{Conclusion}

In the $\mathrm{SnO}_{2}$ thin films grown directly on the $\mathrm{Si}$ substrate, the intensities of (110) plane, (101) plane, and (211) plane exhibited a strengthening tendency to decrease. However, in $\mathrm{SiO}_{2}+$ $\mathrm{SnO}_{2}$ thin films, the (110), (101), and (211) planes exhibited a tendency to decrease slowly, and the growth pattern of $\mathrm{SnO}_{2}$ thin films changed according to the initial production environment of the thin film. The SEM images of the thin films show that $\mathrm{SnO}_{2}$ thin films grown directly on the $\mathrm{Si}$ substrate had a large average particle size with increasing power intensity, and the average particle size interval of the $\mathrm{SnO}_{2}$ thin films grown on the $\mathrm{SiO}_{2}$ layer in the oxygen atmosphere was small. In the Hall effect measurement, the intensity of power supplied to the $\mathrm{SnO}_{2}$ thin film was affected by the surface charge density of the thin film, but the thin film deposited by sintering in the oxygen atmosphere showed the surface charge density. It was confirmed that the $\mathrm{SiO}_{2}$ layer between the substrate and the thin film affects the electrical properties of the thin film owing to the defects in the $\mathrm{SnO}_{2}$ surface and thin film. The optical properties of the thin films grown directly on the substrate were also different from those of the $\mathrm{SnO}_{2}$ thin films grown on the $\mathrm{SiO}_{2}$ layer by sintering in the oxygen atmosphere.

\section{Conflicts of Interest}

The author declares that there are no conflicts of interest regarding the publication of this paper.

\section{References}

[1] H. Cachet, A. Gamard, G. Campet, B. Jousseaume, and T. Toupance, "Tin dioxide thin films prepared from a new alkoxyfluorotin complex including a covalent $\mathrm{Sn}-\mathrm{F}$ bond," Thin Solid Films, vol. 388, no. 1-2, pp. 41-49, 2001.

[2] X. Zhi, G. Zhao, T. Zhu, and Y. Li, “The morphological, optical and electrical properties of $\mathrm{SnO} 2-\mathrm{F}$ thin films prepared by spray pyrolysis," Surface and Interface Analysis, vol. 40, no. 2, pp. 6770, 2008.

[3] J. Qian, P. Liu, Y. Xiao et al., "TiO2-coated multilayered $\mathrm{SnO} 2$ hollow microspheres for dye-sensitized solar cells," Advanced Materials, vol. 21, no. 36, pp. 3617-3667, 2009.

[4] D.-K. Lee, Z. Wan, J.-S. Bae et al., "Plasma-enhanced atomic layer deposition of $\mathrm{SnO} 2$ thin films using $\mathrm{SnCl} 4$ and O2 plasma," Materials Letters, vol. 166, pp. 163-166, 2016.

[5] S. Schiller, G. Beister, and W. Sieber, "Reactive high rate D.C. sputtering: Deposition rate, stoichiometry and features of TiOx 
and TiNx films with respect to the target mode," Thin Solid Films, vol. 111, no. 3, pp. 259-268, 1984.

[6] P.-C. Hsu, S.-P. Tsai, C.-H. Chang et al., "Preparation of ptype $\mathrm{SnO}$ thin films and transistors by sputtering with robust $\mathrm{Sn} / \mathrm{SnO} 2$ mixed target in hydrogen-containing atmosphere," Thin Solid Films, vol. 585, no. 1, pp. 50-56, 2015.

[7] P.-C. Hsu, W.-C. Chen, Y.-T. Tsai et al., "Sputtering deposition of P-type $\mathrm{SnO}$ films using robust $\mathrm{Sn} / \mathrm{SnO} 2$ mixed target," Thin Solid Films, vol. 555, pp. 57-61, 2014.

[8] P.-C. Hsu, C.-J. Hsu, C.-H. Chang et al., "Sputtering deposition of P-type $\mathrm{SnO}$ films with $\mathrm{SnO} 2$ target in hydrogen-containing atmosphere," ACS Applied Materials \& Interfaces, vol. 6, no. 16, pp. 13724-13729, 2014.

[9] J. Jeong, S.-P. Choi, C. I. Chang et al., "Photoluminescence properties of $\mathrm{SnO} 2$ thin films grown by thermal CVD," Solid State Communications, vol. 127, no. 9-10, pp. 595-597, 2003.

[10] J. Jeong and B. J. Lee, "X-ray photoelectron spectroscopy study of $\mathrm{SnO}_{2}$ and $\mathrm{SnO}_{2+x}$ thin films," Journal of Nanoscience and Nanotechnology, vol. 13, no. 1, pp. 711-713, 2013.

[11] S. Min and J. Jeong, "A study of atypical grain growth properties for $\mathrm{SnO}_{2}$ thin films," Materials Science in Semiconductor Processing, vol. 16, no. 5, pp. 1267-1270, 2013.

[12] J. Jeong, "Effect of the Change of Deposition Time on the Secondary Direction and Abnormal Shape of Grains Growth of $\mathrm{SnO}_{2}$ Thin Films," Advances in Materials Science and Engineering, vol. 2015, Article ID 350196, 2015.

[13] A. Cirera, A. Comet, J. R. Morante, S. M. Olaizola, E. Castano, and J. Gracia, "Comparative structural study between sputtered and liquid pyrolysis nanocrystaline SnO2," Materials Science and Engineering: B Advanced Functional Solid-State Materials, vol. 69-70, pp. 406-410, 2000.

[14] J. Jeong, D.-S. Na, B.-J. Lee, H.-J. Song, and H.-G. Kim, "Effects of interface between $\mathrm{SnO}_{2}$ thin film and $\mathrm{Si}$ substrate on growth time," Current Applied Physics, vol. 12, no. 1, pp. 303-306, 2012. 

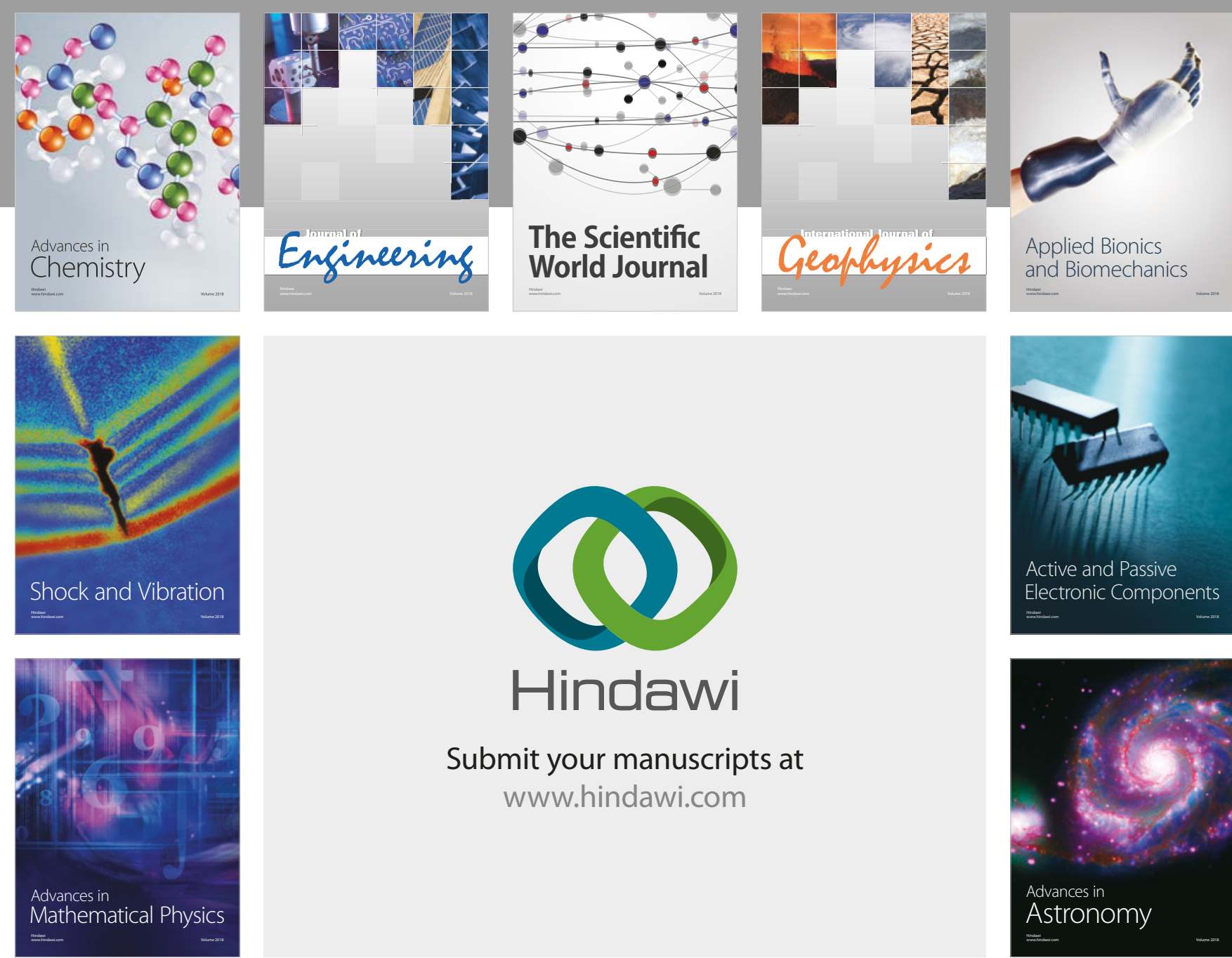

Submit your manuscripts at

www.hindawi.com

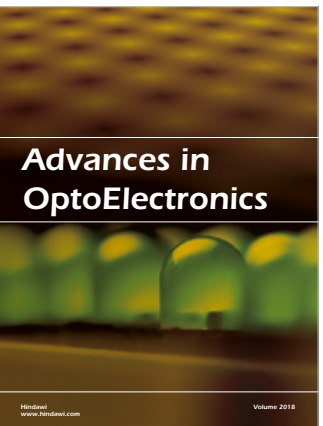

\section{Rotcting Machinery}
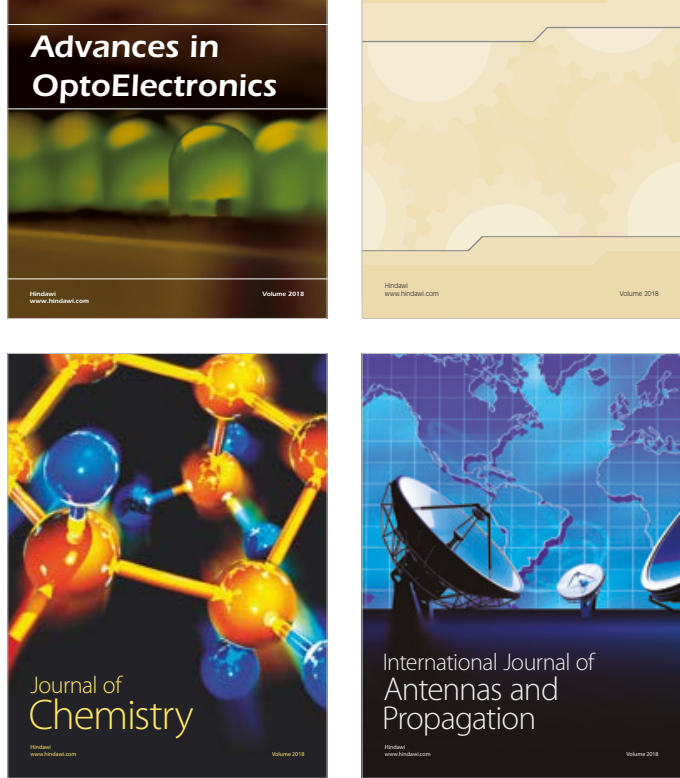

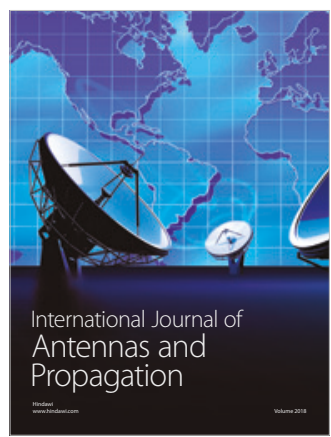

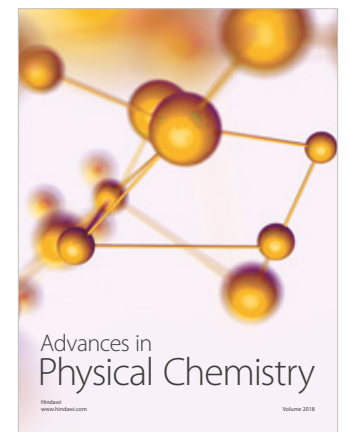

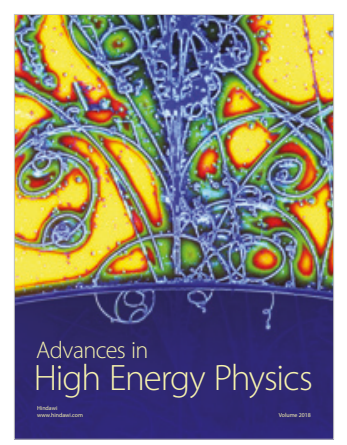

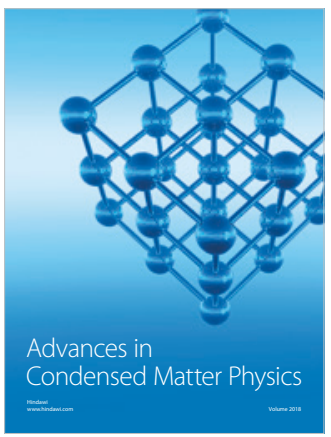

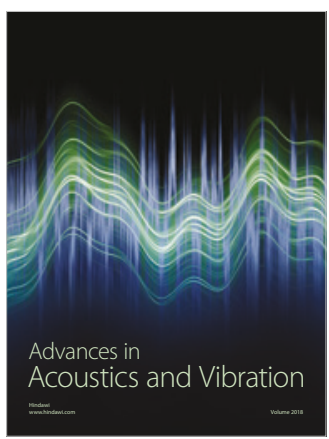

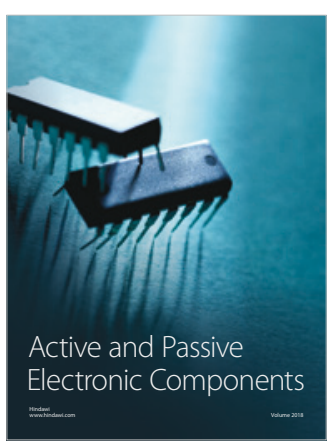
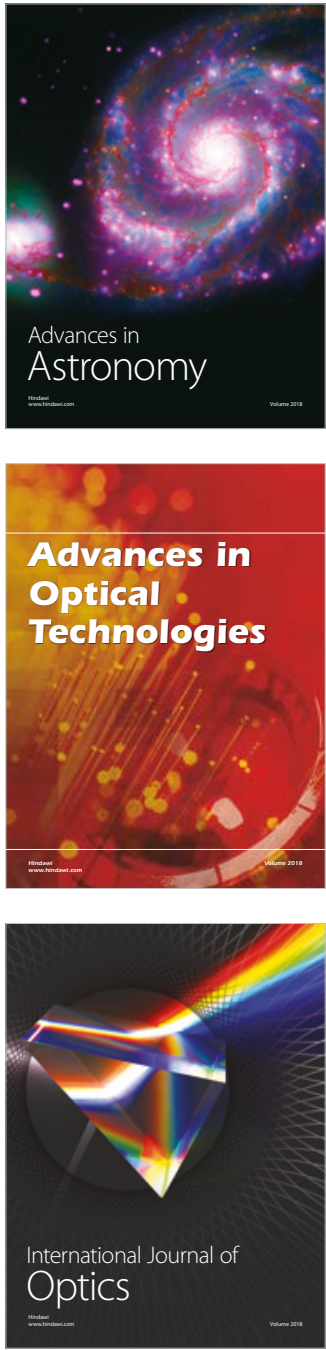